\title{
Simulation of Simplified Model for Kinetics of Biomass Gasification
}

\author{
Cornelius E. Agu ${ }^{1} \quad$ Rajan K. Thapa ${ }^{2} \quad$ Britt M. Halvorsen ${ }^{3}$ \\ Department of Process, Energy and Environmental Technology, Telemark University College, Norway, \\ \{cornelius.e.agu, rajan.k. thapa, britt.halvorsen\} @hit.no
}

\begin{abstract}
Due to complexity in interactions between solid particles and between particles and carrier fluid, modeling of biomass gasification kinetics has been shown to be very challenging. Some commercial packages such as Barracuda VR describe the process using a complicated Eulerian-Lagrangian approach of modeling gas - solid multiphase flow. Since chemical reactions play the major role in the gasification process, this paper focuses on a simplified model that describes the influence of reaction kinetics on the process in a bubbling fluidized bed reactor with circulating bed material. The developed model assumes that the system is ideally mixed with a constant bed temperature. Two different set of reaction rate constants are applied to test the model, and their results are compared with that from Barracuda. The model is used to study the effect of steam-biomass ratio on char conversion, and the results show that the conversion of char increases with steamto-biomass ratio. Sensitivity analysis shows that the output of the model strongly depends on temperature and slightly depends on the bed material particles size.
\end{abstract}

Keywords: Simplified Model, Biomass, Gasification, Fluidized Bed, Kinetics

\section{Introduction}

Biomass gasification process is a technology that has attracted the interest of many researchers recently. This is due to its potential as an alternative to fossil fuels that are major contributors to the environmental degradations. Aside being used as a fuel source for heat and power production, biomass gasification product, called syngas (a mixture of $\mathrm{CO}$ and $\mathrm{H}_{2}$ ) can be used as a feedstock for chemical synthesis.

Gasification of biomass involves its partial combustion in the absence or limited amount of oxygen, mainly with a gasifying agent such as $\mathrm{CO}_{2}$ or steam. In the gasification process, series of physical and chemical activities take place. The process usually begins with drying process, and then followed by pyrolysis. The pyrolysis process leads to breaking down of the biomass into solid matter (charcoal), gaseous mixture (mainly $\mathrm{CO}_{2}, \mathrm{CO}, \mathrm{CH}_{4}$ and $\mathrm{H}_{2}$ ) and liquid matter (tar). The main focus in biomass gasification process is to efficiently convert all the char constituent into gaseous product of the syngas by using either steam or $\mathrm{CO}_{2}$.
Because of the complexities in particle-fluid and particle-particle interactions, modeling a complete set of biomass activities has been proven to be somewhat challenging. However, with introduction of appropriate assumptions, several attempts have been made with some successful results. Most of the existing models are centered around chemical kinetics, thermodynamics and transport of species in the reactor. Chemical kinetics play the largest role in the process since the conversion of char is mainly by chemical means. By inclusion of transport of mass, momentum and energy, the concentration gradient of the reacting species over the reaction chamber can be well captured.

The main objective of this paper is to study the reaction kinetic influences on the gasification process in bubbling fluidized bed reactor with circulating bed material. The bubbling fluidized bed reactor ensures a uniform heat distribution, and with a circulating bed material, a constant heat supply is maintained. The basic arrangement for such a system is shown in Figure 1.

Among several studies, (Lü et al, 2008; Fiaschi and Michelini, 2001) studied the gasification kinetics based on steady state 1-D model for two-phase systems distinguished by bubbling and emulsion phases. The studies consider the effects of hydrodynamics of the species in the reactor. (Farooq et al, 2013) uses $\mathrm{CO}_{2}$ as a gasifying agent to study the influence of temperature and partial pressure on char conversion rate. (Xu et al, 2011) studied the conversion rate of char with a 1-D dynamic model that accounts for the effects of mass and heat transfer, and concluded that the char conversion depends on the exposed surface area and the micro-pore size of the particles in a fixed bed reactor.

In this work, char conversion rate with steam as the gasifying agent, and influences of steam-biomass ratio on the conversion rate in bubbling fluidized bed reactor with circulating bed material, are studied. A simplified model describing the concentration of each species over time is developed. The model accounts for mass fraction of char particles in the outflow of the bed material, and effective porosity of the total solid in the system. The proposed model excludes the influence of convective and diffusive transport of conserved properties. The model is used to investigate the influence of kinetics rate constants on reaction mechanism of the gasification process by comparing its results with those from a detailed 3-D model based on Barracuda VR. The model 
sensitivities to temperature and bed material' particle size are also analyzed.

In the following sections, the governing equations are presented and a complete model for an ideally mixed reactor is developed. The model results based on two different reaction rate constants are compared for both variations in time and in steam-biomass ratio. Finally, some conclusions are drawn.

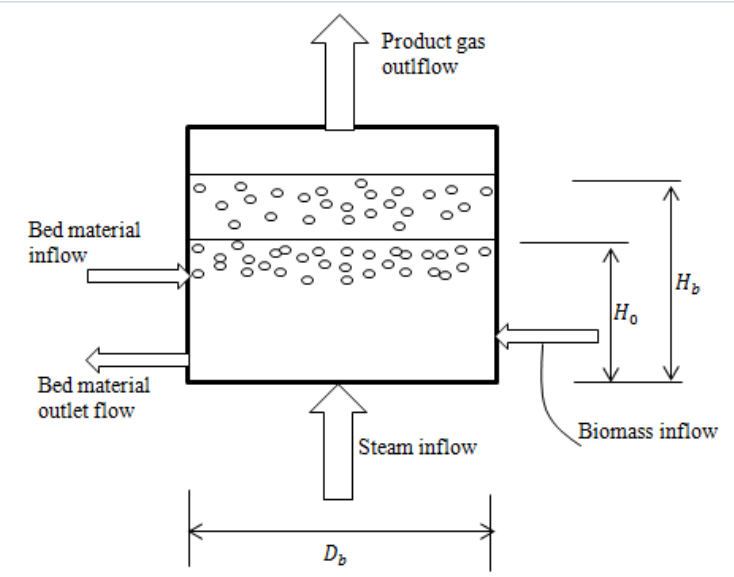

Figure 1. Bubbling Fluidized Bed Reactor with Circulating Bed Material.

\section{Governing Equations}

The model describing the gasification process in the reactor (Figure 1) is formulated based on a one-step pyrolysis process and the competitive reactions of gaseous species in both heterogeneous and homogeneous phases.

- Pyrolysis

$$
\begin{array}{lll}
\text { Biomass } & \stackrel{r_{1}}{\rightarrow} \text { volatile } \\
\text { Biomass } & \stackrel{r_{2}}{\rightarrow} \text { char }
\end{array}
$$

Here, the tar concentration is neglected. It is assumed that the product of complete pyrolysis contains $91 \%$ volatiles and $9 \%$ char by weight (Thapa et al, 2014). The only gases considered among the volatiles are $\mathrm{CO}_{2}, \mathrm{CO}$ and $\mathrm{H}_{2}$, and their compositions are given in Table 1 (Thapa et al, 2014).

Table 1. Light Gases from Biomass Pyrolysis.

\begin{tabular}{|l|l|}
\hline Volatile Component & Composition, $v$ (wt\%) \\
\hline $\mathrm{CH}_{4}$ & 0.1213 \\
\hline $\mathrm{CO}$ & 0.6856 \\
\hline $\mathrm{CO}_{2}$ & 0.1764 \\
\hline $\mathrm{H}_{2}$ & 0.0167 \\
\hline $\mathrm{H}_{2} \mathrm{O}$ & 0.0 \\
\hline
\end{tabular}

- Heterogeneous reaction

$$
\begin{array}{lll}
\mathrm{C}+\mathrm{H}_{2} \mathrm{O} & \stackrel{r_{3}}{\rightarrow} & \mathrm{CO}+\mathrm{H}_{2} \\
\mathrm{C}+\mathrm{CO}_{2} & \stackrel{r_{4}}{\rightarrow} & 2 \mathrm{CO}
\end{array}
$$

- Homogeneous reaction

$$
\mathrm{CO}+\mathrm{H}_{2} \mathrm{O} \stackrel{r_{5}}{\rightarrow} \mathrm{CO}_{2}+\mathrm{H}_{2}
$$

\subsection{Model Formulation}

The following further assumptions are applicable in formulating the model.

(1). Both the bed material and char particles have constant sizes.

(2). The temperature of the reactor is constant and uniform across the reactor axis, which is achievable with constant particle sizes and sufficient bubbling effect of fluidization including homogeneity in the mixture.

(3). There is no phase separation for the same species involving in both heterogeneous and homogeneous phase reactions.

(4). The pyrolysis process is very fast, and all the biomass is converted into char and volatiles as it is being introduced into the reactor.

Applying a species mass balance for an ideally mixed system

$$
\frac{d m}{d t}=\dot{m}_{\text {in }}-\dot{m}_{\text {out }}+\dot{m}_{g e n}
$$

For biomass, $m=\rho_{B} V_{b}, \dot{m}_{\text {out }}=0$ and $\dot{m}_{\text {gen }}=V_{b} R_{B}$, and these give

$$
\frac{d \rho_{B}}{d t}=\frac{\dot{m}_{B, i n}}{V_{b}}+R_{B}
$$

Here, $\rho_{B}$ is the mass concentration of biomass in the reactor. $V_{b}$ is the reaction volume and $R_{B}$ is the rate of biomass pyrolysis described by reactions R1 and R2. $\dot{m}_{B, \text { in }}$ is mass flow rate of biomass into the reactor.

The reaction rate constants $r_{1}$ and $r_{2}$ in $\mathrm{R} 1$ and $\mathrm{R} 2$ respectively are given in Arrhenius form (Haseli et al, 2011)

$$
r_{i}=A_{i} \exp \left(-\frac{E_{i}}{R T}\right) ; i=1,2 .
$$

Here, $T$ and $R$ are temperature in Kelvin and gas constant in $\mathrm{J} /(\mathrm{mol} . \mathrm{K})$. The pre-exponential rate constant $A$ and the activation energy $E$ of the reactions according to (Fantozzi et al, 2007) are given as $1.44 \times 10^{4} \mathrm{~s}^{-1}$ and $88.6 \times 10^{3} \mathrm{~J} / \mathrm{mol}$, respectively for $\mathrm{R} 1$, and $7.38 \times 10^{5} \mathrm{~s}^{-1}$ and $106.5 \times 10^{3} \mathrm{~J} / \mathrm{mol}$, respectively for R2. $R_{B}$ is given as

$$
R_{B}=-\left(r_{1}+r_{2}\right) \rho_{B}
$$

For the reactions R3-R5, the species concentrations are given in $\mathrm{mol} / \mathrm{m}^{3}$. Equation (4) gives the general species balance in the reactor.

$$
\begin{aligned}
& \frac{d C_{j}}{d t}=\dot{C}_{j, \text { in }}-\dot{C}_{j, \text { out }}+R_{j} \\
& j=C, \mathrm{H}_{2} \mathrm{O}, \mathrm{CO}_{2}, \mathrm{CO}, \mathrm{H}_{2}
\end{aligned}
$$


For char, $C$ particles

$$
\dot{C}_{C, \text { in }}=w_{p c} r_{2} \rho_{B} / M_{C}
$$

Here, $w_{p c}$ is the weight fraction of char in the pyrolysis product and $M_{C}$ is the molecular weight of carbon. The outflow concentration of char depends on circulation rate of the bed material. Assuming a homogenous mixture of char and bed material particles in the reactor,

$$
\dot{C}_{C, \text { out }}=\frac{w_{c} \dot{m}_{b}}{V_{b} M_{C}} .
$$

Here, $w_{c}$ is the weight fraction of char in the solid mixture, and $\dot{m}_{b}$ is mass circulation rate of the bed material. Based on a uniform distribution of solid particles in the reactor, the expression for $w_{c}$ is derived and given by

$$
w_{C}=\frac{M_{C} C_{C}}{\left(s_{r}-1\right)\left(\bar{\rho}_{C}-M_{C} C_{C}\right)+\bar{\rho}_{C}} .
$$

Here, $s_{r}=\bar{\rho}_{b} / \bar{\rho}_{C}$ is solid mass loading ratio, $\bar{\rho}_{b}=\varepsilon_{b} \rho_{b}$ is bulk density of the bed material, and $\bar{\rho}_{C}=\varepsilon_{C} \rho_{C}$ is bulk density of char. $\rho_{b}$ and $\rho_{C}$ are the densities of bed material and char, respectively, and their respective volume fractions are $\varepsilon_{b}$ and $\varepsilon_{C}$.

Again, the effective volume fraction $\varepsilon_{S}$ of the solid particles in the reactor is given by

$$
\varepsilon_{S}=\varepsilon_{b}+\frac{M_{C} C_{C}}{\rho_{C}}\left(1-\varepsilon_{b} / \varepsilon_{C}\right) .
$$

Since the amount of char decreases as the reaction goes, the total reaction volume decreases with char conversion. Assuming that circulation of the bed material is in steady state, the instantaneous reaction volume can be obtained from

$$
V_{b}=\left(\frac{\varepsilon_{s}}{1-\varepsilon_{f}}\right) \frac{V_{0}}{\left(1-\frac{M_{C} C_{C}}{\bar{\rho}_{C}}\right)} .
$$

Here, $V_{0}=A_{b} H_{0}$ is the solid volume of bed material, with $H_{0}$ its solid height and $A_{b}=\pi D_{b}^{2} / 4$ the reactor cross sectional area, where $D_{b}$ is the bed diameter. $\varepsilon_{f}$ is the average voidage of the bed under bubbling influence. It should be noted that because of lack of space, derivations of Eq. (7)-(9) are not part of this paper.

The decrease in char residue concentration due to its conversion is expressed as

$$
R_{C}=-\left(r_{3}+r_{4}\right)
$$

For each of the gaseous species,

$$
\begin{aligned}
& \dot{C}_{j, \text { in }}=w_{p v} v_{j} r_{1} \rho_{B} / M_{j} \\
& j=\mathrm{CO}_{2}, \mathrm{CO}, \mathrm{H}_{2} .
\end{aligned}
$$

For steam, $\mathrm{H}_{2} \mathrm{O}$

$$
\dot{C}_{H_{2} O, i n}=\frac{w_{p v} v_{H_{2} O} r_{1} \rho_{B}}{M_{H_{2} O}}+\frac{\dot{m}_{\text {steam }}}{V_{b} M_{H_{2}} \mathrm{O}} .
$$

Here, $w_{p v}$ is the weight fraction of total volatile matters in the pyrolysis product and $M_{j}$ is molecular weight of the $j$ species. $v_{j}$ is weight fraction of the species in the volatiles after pyrolysis. $\dot{m}_{\text {steam }}$ is steam mass flow rate into the reactor.

The decrease in concentration of each species due to gas product outflow from the reactor depends on concentration of the species at exit of the reactor, and on the fluidization velocity. Assuming ideal gas behaviour, and that the gas outlet is subjected to atmospheric pressure,

$$
\begin{aligned}
& \dot{C}_{j, \text { out }}=\left(C_{j}-\frac{x_{j} P_{0}}{R T}\right) \frac{\dot{V}_{g}}{V_{b}} \\
& x_{j}=C_{j} / \sum C_{j} .
\end{aligned}
$$

$x_{j}$ is the mole fraction of species $j$ in the gas phase mixture and $P_{0}$ is the atmospheric pressure. The reciprocal of $\frac{\dot{V}_{g}}{V_{b}}$ defines the reaction residence time. The gas volumetric flow rate $\dot{V}_{g}$ is given by

$$
\dot{V}_{g}=A_{b}\left(u_{0}-u_{m f}\right) \text {. }
$$

Here, $u_{0}=\frac{\dot{m}_{\text {steam }}}{f A_{b} \rho_{\text {steam }}}$ is superficial gas velocity of the approaching gasifying agent (steam) and $u_{m f}$ is the minimum fluidization velocity. $u_{m f}$ can be obtained from Eq. (15) (Radmanesh et al, 2006). $f$ is a reduction factor of the bed cross sectional area which ensures high fluidization velocity. In this work, a value of 0.2 is used.

$$
\begin{gathered}
u_{m f}=\frac{\mu_{g}}{d_{p} \rho_{g}} \sqrt{\left(27.2^{2}+0.0408 A r\right)}-27.2 \\
A r=\frac{d_{p}^{3} \rho_{g}\left(\rho_{s}-\rho_{g}\right) g}{\mu_{g}^{2}}
\end{gathered}
$$

Here, $\mu_{g}$ and $\rho_{g}$ are gas mixture viscosity and density, respectively. $d_{p}$ is solid particle diameter, and $g$ is acceleration due to gravity.

The gas mixture density can be obtained from Eq. (16). The viscosity of gas mixture is given by Eq. (17) (Herning and Zipperer, 1936), in which $\mu_{j}$ is the individual species viscosity.

$$
\begin{aligned}
\rho_{g} & =\frac{1}{1-\varepsilon_{s}} \sum C_{j} \sum\left(x_{j} M_{j}\right) \\
\mu_{g} & =\frac{\sum\left(\mu_{j} x_{j} \sqrt{M_{j}}\right)}{\sum\left(x_{j} \sqrt{M_{j}}\right)}
\end{aligned}
$$


The average bed voidage at bubbling fluidization can be obtained from

$$
\varepsilon_{f}=\delta+(1-\delta) \varepsilon_{m f} .
$$

The minimum fluidization voidage $\varepsilon_{m f}$ is given by Eq. (19) and the bubble fraction in the bed $\delta$ can be obtained from Eq. (20).

$$
\begin{aligned}
& \frac{1}{\emptyset_{s} \varepsilon_{m f}^{3}} \approx 14 \\
& \delta=\frac{u_{0}-u_{m f}}{u_{b}}
\end{aligned}
$$

Here, $u_{b}$ is the bubble rise velocity, which can be obtained by

$$
u_{b}=u_{0}-u_{m f}+0.711 \sqrt{g D_{b}} .
$$

$D_{b}$ is the average bubble diameter over the bed, and can be obtained by

$$
D_{b}=\frac{0.30\left(u_{0}-u_{m f}\right)^{0.4} H_{b} 0.8}{g^{0.2}} .
$$

$H_{b}$ is the initial bed height. The overall generation rates of the species, assuming forward reactions as given in R3 - R5 are

$$
\begin{aligned}
& R_{\mathrm{H}_{2} \mathrm{O}}=-\left(r_{3}+r_{5}\right) \\
& R_{\mathrm{CO}_{2}}=-r_{4}+r_{5} \\
& R_{C O}=r_{3}+2 r_{4}-r_{5} \\
& R_{\mathrm{H}_{2}}=r_{3}+r_{5} .
\end{aligned}
$$

\subsection{Reaction Rate Constants}

The success of every chemical kinetic model depends on rate constants of the reactions. Several models for reaction rate constants are published in the literature. Since the main objective of this paper is to investigate the influence of reaction rate constants on biomass gasification, two set of models used in (Xie et al, 2012) and (Braun et al, 1981) are utilized, and their results are compared. The rate constants given for the pyrolysis process are applied in both cases. Table 2 gives a summary of these models as applied in each of the cases. The rate constants are expressed in $\mathrm{mol} /\left(\mathrm{m}^{3} . \mathrm{s}\right)$.

The models in Case 1 account for reversibility, and for influence of char residue in the heterogeneous reactions $\mathrm{R} 3$ and $\mathrm{R} 4$. In addition to effects of char residue in the heterogeneous reactions, Case 2 takes into account the porosity of total solid particles in the homogeneous reaction. The generation rates of the species in Case 1 are given by

$$
R_{C}=\left(r_{3 r}+r_{4 r}\right)-\left(r_{3 f}+r_{4 f}\right)
$$

$$
\begin{aligned}
& R_{\mathrm{H}_{2} \mathrm{O}}=r_{3 r}-\left(r_{3 f}+r_{5}\right) \\
& R_{\mathrm{CO}_{2}}=\left(r_{4 r}+r_{5}\right)-r_{4 f} \\
& R_{C O}=\left(r_{3 f}+2 r_{4 f}\right)-\left(r_{3 r}+2 r_{4 r}+r_{5}\right) \\
& R_{\mathrm{H}_{2}}=\left(r_{3 f}+r_{5}\right)-r_{3 r}
\end{aligned}
$$

$m_{s}$ in Case 1 model is the mass of a single carbon particle, and it is modeled as in Eq. (25).

$$
\frac{d m_{s}}{d t}=\left(1-\varepsilon_{C}\right) \frac{M_{C}}{\bar{\rho}_{C}} m_{s} \frac{d C_{C}}{d t}
$$

Based on the ideal gas behaviour, Eq. (26) gives the pressure, $P$ in the reactor.

$$
\begin{aligned}
& P=R T \sum C_{j} \\
& j=H_{2} O, \mathrm{CO}_{2}, \mathrm{CO}, \mathrm{H}_{2}
\end{aligned}
$$

\subsection{Char Conversion Factor}

Char conversion factor, $X_{C}$ describes the progress and efficiency of biomass gasification process. $X_{C}$ given by Eq. (27), expresses how much of char is converted relative to its original concentration in the reactor.

$$
X_{C}=\frac{C_{C, 0}-C_{C}}{C_{C, 0}}
$$

Here, $C_{C, 0}$ is the initial char concentration.

\subsection{Initial Conditions}

Assuming that the bed is initially filled with hot bed material and product of biomass pyrolysis (char and volatiles), the initial concentration of species in the reactor are obtained as follows.

$$
C_{C, 0}=\varepsilon_{C} \frac{V_{C}}{V_{b}} \frac{\rho_{C}}{M_{C}}
$$

The volume ratio, $\frac{V_{C}}{V_{b}}$ can be obtained from Eq. (29)

$$
\frac{V_{C}}{V_{b}}=1-\left(\frac{w_{p c}}{r_{m}} s_{r}+1\right)^{-1}
$$

Here, $r_{m}$ is the solid mass mixing ratio of bed material to biomass.

For each of gas species, assuming the pressure in the reactor is initially atmospheric,

$$
\begin{gathered}
C_{j, 0}=\frac{x_{j, 0} P_{0}}{R T}\left(1-\varepsilon_{s, 0}\right) \\
x_{j, 0}=\frac{v_{j}}{M_{j}} / \sum\left(\frac{v_{j}}{M_{j}}\right)
\end{gathered}
$$

$m_{s, 0}=\frac{\pi}{6} d_{c}^{3} \rho_{C}$, where $d_{C}$ is the diameter of single char particle. $\rho_{B, 0}=0$. 
Table 2. Kinetic Rate Constants for Biomass Gasification Reaction

\begin{tabular}{|c|c|c|}
\hline Reactions & Case 1 (Xie et al, 2012) & Case 2 (Braun et al, 1981) \\
\hline R3 & $\begin{array}{c}r_{3 f}=1.272 m_{s} T \exp \left(-\frac{22645}{T}\right) C_{\mathrm{H}_{2} \mathrm{O}} \\
r_{3 r}=1.044 x 10^{-4} m_{s} T^{2} \exp \left(-\frac{6319}{T}\right. \\
-17.29) C_{\mathrm{H}_{2}} C_{C O}\end{array}$ & $\begin{array}{r}r_{3}=\frac{k_{1} P_{\mathrm{H}_{2} \mathrm{O}}}{1+k_{2} P_{\mathrm{H}_{2}}+k_{3} P_{\mathrm{H}_{2} \mathrm{O}}} \frac{C_{C}^{2}}{C_{C, 0}} \\
k_{1}=1.25 \times 10^{5} \exp \left(-\frac{28000}{T}\right) \\
k_{2}=3.26 \times 10^{-4} \\
k_{3}=0.313 \exp \left(-\frac{10120}{T}\right)\end{array}$ \\
\hline R4 & $\begin{array}{c}r_{4 f}=1.272 m_{s} T \exp \left(-\frac{22645}{T}\right) C_{\mathrm{CO}_{2}} \\
r_{4 r}=1.044 \times 10^{-4} m_{s} T^{2} \exp \left(-\frac{2363}{T}\right. \\
-20.92) C_{C O}{ }^{2}\end{array}$ & $\begin{array}{c}r_{4}=\frac{k_{4} C_{C}}{1+\frac{x_{C O}}{k_{C 4} x_{C O_{2}}}} \\
k_{4}=3.6 \times 10^{5} \exp \left(-\frac{20130}{T}\right) \\
k_{c 4}=4.15 \times 10^{3} \exp \left(-\frac{11420}{T}\right)\end{array}$ \\
\hline R5 & $\begin{array}{c}r_{5}=2.78 x 10^{3} \exp \left(-\frac{1510}{T}\right)\left[C_{C O} C_{H_{2} O}\right. \\
\left.-C_{C_{2} O_{2}} C_{H_{2}} / k_{c 3}\right] \\
k_{c 3}=0.0265 \exp \left(\frac{3968}{T}\right)\end{array}$ & $\begin{array}{c}r_{5}=k_{5}\left(x_{C O} x_{\mathrm{H}_{2} \mathrm{O}}-\frac{x_{\mathrm{CO}_{2}} x_{\mathrm{H}_{2}}}{k_{c 5}}\right)\left(\frac{P}{R T}\right)^{2} \varepsilon_{f} \\
k_{5}=377 \exp \left(-\frac{7300}{T}\right) \\
k_{c 5}=0.017 \exp \left(\frac{4400}{T}\right)\end{array}$ \\
\hline
\end{tabular}

\section{Results and Discussion}

The parameters used in this work are given in Table 3, where the variable, $S_{b r}$ is the steam-to-biomass ratio. The simulation is based on constant solid mass mixing ratio $r_{m}$.

\subsection{Comparison with Barracuda Results}

The gas-particle flow in the reactor is simulated in three dimensions using the commercial solver Barracuda VR 15. The Computational Particle Fluid Dynamic model is based on the Eulerian-Lagrangian approach of modeling gas-solid multiphase flow (Snider and Banerjee, 2010). The approach treats solid phase as discrete elements. The motion of individual particle is tracked using Newton's law. The particle-particle, particle-wall and fluid-particle interactions are taken into account (Boyalakuntla, 2003). The approach makes it possible to solve the gas-particle system with a wide range of particle size distribution (Amsden et al, 1989).

The evolution of mole fractions of the gas composition in the reactor based on the developed simplified (ideally mixed) model and based on the Barracuda (3D) model are compared in Figures 2 and 3, for a steam-biomass ratio of 0.6. The Barracuda result is obtained by simulating the $3 \mathrm{D}$ model in a reactor of $2 \mathrm{~m}$ high including the freeboard space under the same cond- itions as given in Table 2. The 3D model results shown are the composition of the gaseous product just at the top of the bed.

Figure 2 shows that Case 1 model seems to show little or no conversion. Except water, all other compositions show decreasing trend with time, which differ widely from the 3D model results. On the other hand, Figure 3 shows that Case 2 model gives a similar

Table 2. Parameters for Model Computation.

\begin{tabular}{|c|c|c|}
\hline Parameters & Values & Units \\
\hline$d_{b}$ & 0.5 & $\mathrm{~mm}$ \\
\hline$d_{c}$ & 2.0 & $\mathrm{~mm}$ \\
\hline$\varepsilon_{b}$ & 0.6 & - \\
\hline$\varepsilon_{C}$ & 0.3 & - \\
\hline$H_{0}$ & 0.40 & $\mathrm{~m}$ \\
\hline$D_{b}$ & 0.55 & $\mathrm{~m}$ \\
\hline$T$ & 1100 & $\mathrm{~K}$ \\
\hline$P_{0}$ & 1.01 & bar \\
\hline$r_{m}$ & 40 & - \\
\hline$\rho_{b}$ & 2960 & $\mathrm{~kg} / \mathrm{m}^{3}$ \\
\hline$\rho_{C}$ & 200 & $\mathrm{~kg} / \mathrm{m}^{3}$ \\
\hline$\rho_{\text {steam }}$ & 0.204 & $\mathrm{~kg} / \mathrm{m}^{3}$ \\
\hline$\dot{m}_{\text {steam }}$ & $4.0 \times 10-3$ & $\mathrm{~kg} / \mathrm{s}$ \\
\hline$\dot{m}_{B, i n}$ & $\frac{\dot{m}_{\text {steam }}}{S_{b r}}$ & $\mathrm{~kg} / \mathrm{s}$ \\
\hline$\dot{m}_{b}$ & $r_{m} \dot{m}_{B, i n}$ & $\mathrm{~kg} / \mathrm{s}$ \\
\hline
\end{tabular}


trend to Barracuda and predicts except $\mathrm{H}_{2}$, compositions of $\mathrm{CO}_{2}, \mathrm{CO}$ and $\mathrm{H}_{2} \mathrm{O}$ closer to the 3D model. The high discrepancy in the mole fraction of $\mathrm{H}_{2}$ (Case 2) could be due to non-inclusion of $\mathrm{CH}_{4}$ in the simplified model simulation, which was considered in the $3 \mathrm{D}$ model. Because of similarities in the result trends, the proposed model can be used to study the effect of variables such as steam-biomass ratio that influence the gasification process.

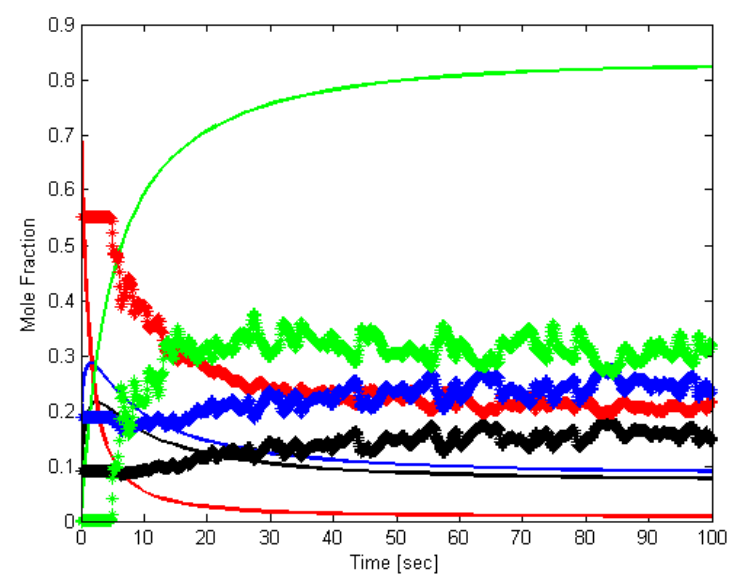

Figure 2. Comparison with 3D Model for Case 1.

Green $=\mathrm{H}_{2} \mathrm{O}$, Blue $=\mathrm{H}_{2}, \mathrm{Red}=\mathrm{CO}$, Black $=\mathrm{CO}_{2}$ Ideally mixed: Solid lines; $3 D$ model: Saw-toothed

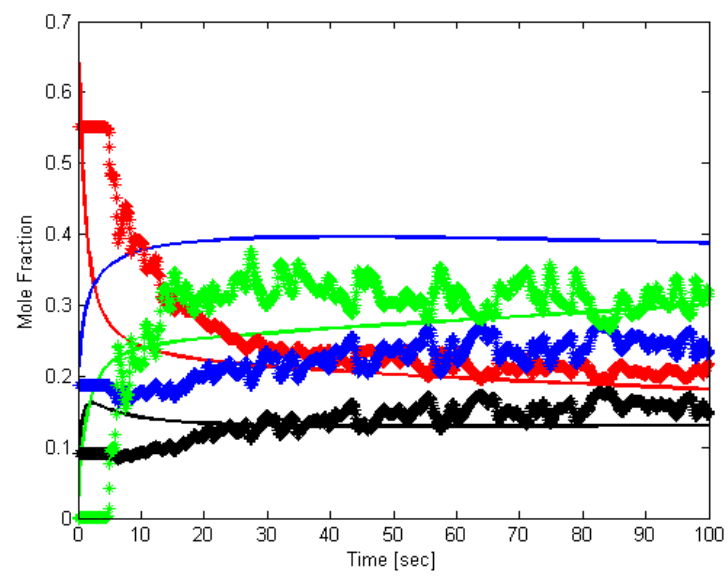

Figure 3. Comparison with 3D model for Case 2.

Green $=\mathrm{H}_{2} \mathrm{O}$, Blue $=\mathrm{H}_{2}$, Red $=\mathrm{CO}$, Black $=\mathrm{CO}_{2}$ Ideally mixed: Solid lines; 3D model: Saw-toothed

\subsection{Conversion versus Time}

Using the parameters in Table 3 and steam to biomass ratio of 0.25 , the model developed in this paper is simulated using MATLAB ode solver. Figure 4 compares the char conversion factor obtained from both models in Case 1 and Case 2. The Case 1 result shows that less than $10 \%$ conversion can be achieved in 10 minutes. In Case 2, the result shows an appreciably increase in conversion factor, giving over $45 \%$ conversion at the end of 10 minutes. Figure 5(a) shows that the concentration of unconverted water in the system is higher in Case 1 than in Case 2, and this confirms why the difference in the conversion factor obtained in the two cases.

Figures 5(b-d) show the evolution of concentration of $\mathrm{CO}_{2}, \mathrm{CO}$ and $\mathrm{H}_{2}$, respectively for both cases. Both cases show similar trends in $\mathrm{CO}_{2}$ concentration, but Case 2 gives higher values over time. It can be seen from the results that the concentrations of $\mathrm{CO}_{2}, \mathrm{CO}$ and $\mathrm{H}_{2}$ in Case 1 remain the same after 1 minute. This indicates that the product gas is mainly from pyrolysis process with little or none from gasification process. The corresponding concentrations in Case 2 are higher over time, possibly due to higher char conversion and more activities in the water gas shift reaction (R5). The slight decrease in $\mathrm{H}_{2}$ in this case after attaining maximum concentration may be due to a decrease in char residue and retardation in water gas shift reaction due to decreasing $\mathrm{CO}$ concentration within this period as shown in Figure 5(c).

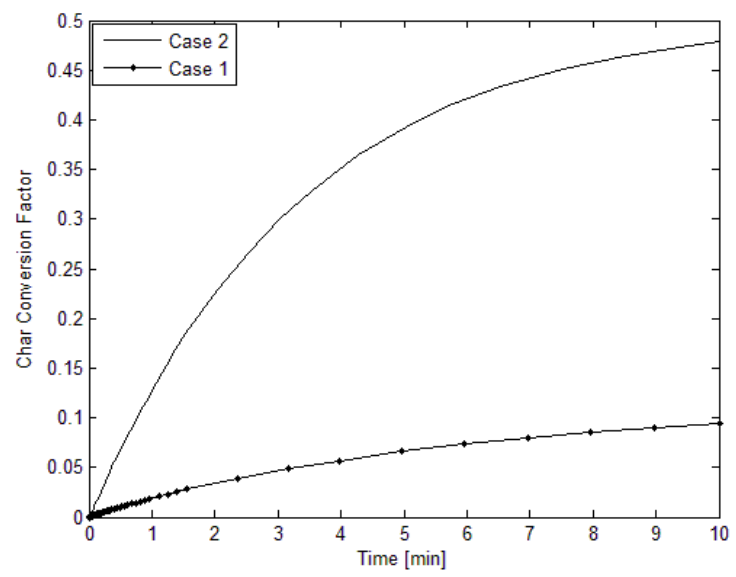

Figure 4. Evolution of Char Conversion Factor.

\subsection{Conversion versus Steam-to-Biomass Ratio}

The effect of steam-biomass ratio, $S_{b r}$ is represented by the results in Figures (6-8). The results for each $S_{b r}$ correspond to the values at the 10th minute. Figure 6 compares the trend of char conversion with steambiomass ratio for both cases. The result trends from both cases are exactly opposite. Case 1 show a decreasing conversion factor as steam-biomass ratio increases. However, in Case 2, $X_{C}$ increases as $S_{b r}$ increases. The increasing value of conversion factor in Case 2 can be attributed to the reduction in amount of biomass into the reactor since higher $S_{b r}$ indicates lower biomass flow rate.

Comparing Figures 7 and 8 (variation of mole fractions of the product gas composition with $S_{b r}$ ), it can be seen that both have similar trend. Both show decrease in amount of $\mathrm{CO}_{2}, \mathrm{CO}$ and $\mathrm{H}_{2}$ and increase in amount of water, but Case 2 gives higher values for $\mathrm{CO}_{2}, \mathrm{CO}$ and $\mathrm{H}_{2}$, and lower values for $\mathrm{H}_{2} \mathrm{O}$ due to higher conversions. The decrease in the gas compositions may be due to less contribution from pyrolysis as $S_{b r}$ increases. 


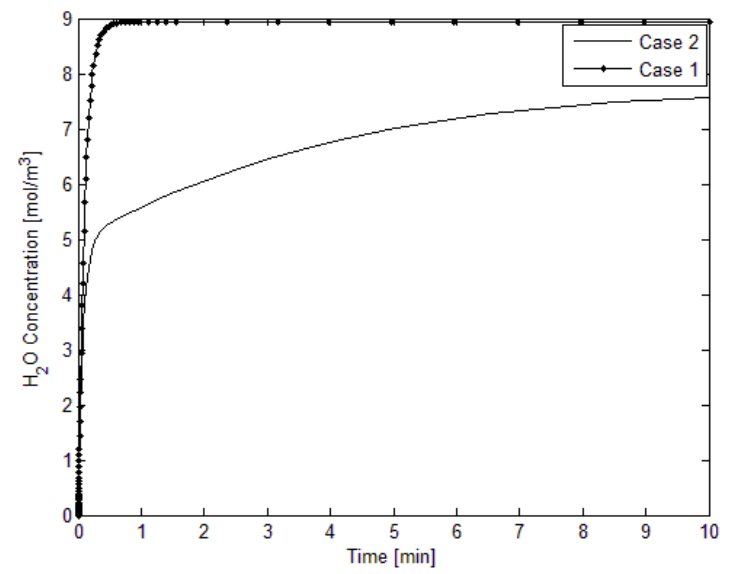

(a)

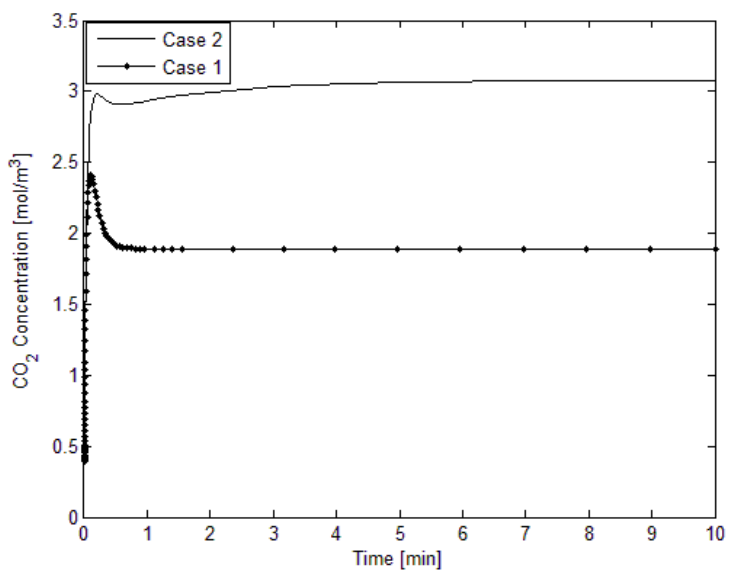

(b)

Figure 5 (a-d). Evolution of Product

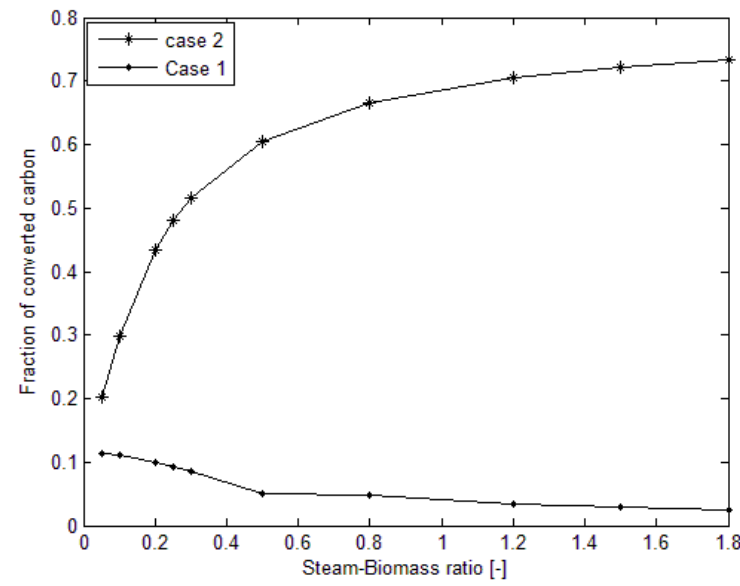

Figure 6. Effect of Steam-Biomass Ratio on Char.

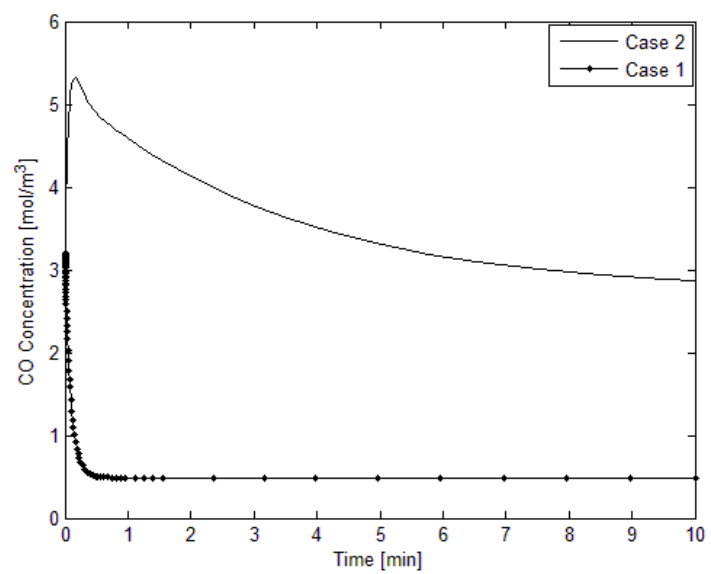

(c)

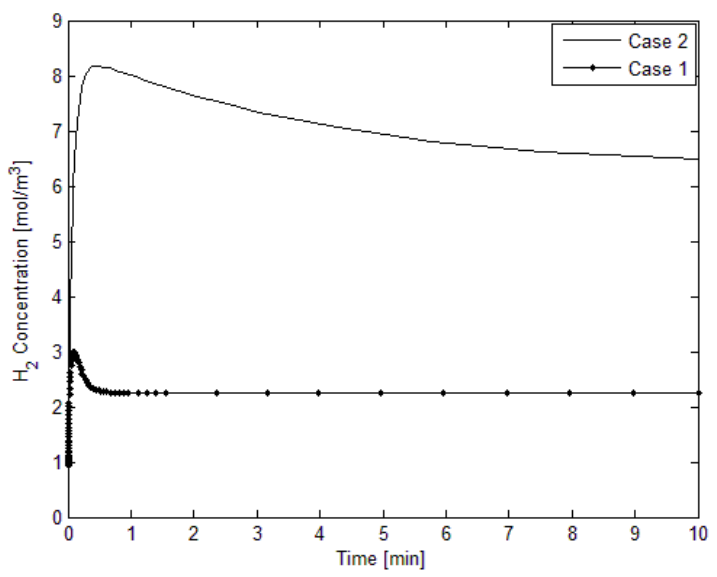

(d)

Gas Concentration.

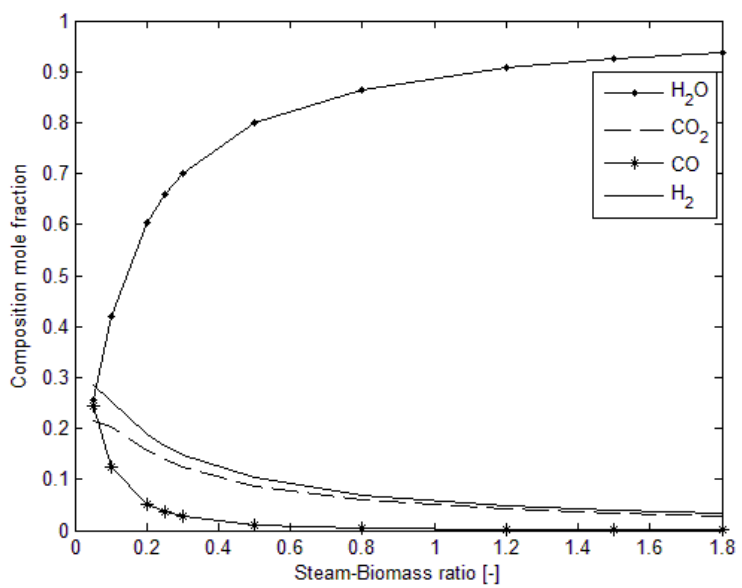

Figure 7. Effect of Steam-Biomass Ratio on Product Composition (Case 1). 


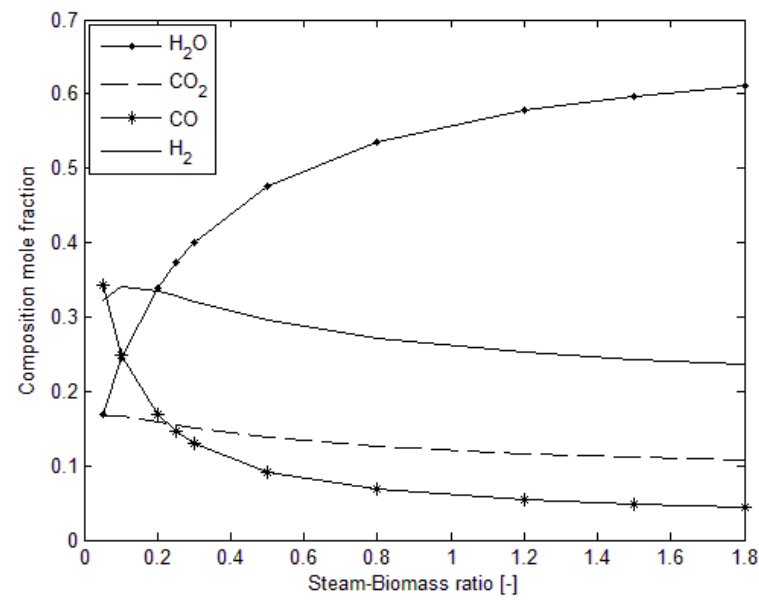

Figure 8. Effect of Steam-Biomass Ratio on Product Composition (Case 2).

\subsection{Model Sensitivity}

There are certain parameters of the model that are not certainly correct based on the simplified assumptions. Such parameters include temperature distribution and particle sizes of the bed material and char. The results obtained from the simplified model are based on the average bed material' particle diameter and on the mean reaction temperature. Sensitivity of the model to deviation of these parameters from the mean values, and to uncertainty in the parameter measurement, is analyzed here. The sensitivity measures the relative change in any output of the model due to relative change in any parameter of the model as expressed in Eq. (31).

$$
S=\frac{\left(\frac{\Delta X}{X_{0}}\right)}{\left(\frac{\Delta Y}{Y_{0}}\right)}
$$

Here, $S$ is the sensitivity, $X_{0}$ and $Y_{0}$ are the model output and parameter, respectively, at the operating point. $\Delta Y$ is the deviation of the parameter from the operating point and $\Delta X$ is the corresponding deviation of the model output.

Figures 9 and 10 show the relative change in char conversion factor, and in $\mathrm{CO}$ and $\mathrm{H}_{2}$ concentrations, due to relative change in temperature and bed material' particle diameter, respectively, based on Case 2 model. From Figure 9, the sensitivity of the model in response to temperature change is 6.82 for char conversion, 7.27 for $\mathrm{CO}$ and 2.07 for $\mathrm{H}_{2}$. This implies that for every $1 \%$ change in temperature, keeping other parameters constant, the char conversion increases by $6.82 \%$, and $\mathrm{CO}$ and $\mathrm{H}_{2}$ concentrations increase by $7.27 \%$ and $2.07 \%$, respectively. The result in Figure 10 suggests that output of the model decreases for any increase in the bed material' particle size, keeping other parameters constant. The sensitivity to change in the material particle size is very low, giving $0.015 \%, 0.040 \%$ and $0.016 \%$ decrease in char conversion, $\mathrm{CO}$ and $\mathrm{H}_{2}$ concentrations, respectively, for every $1 \%$ increase in the particle size.

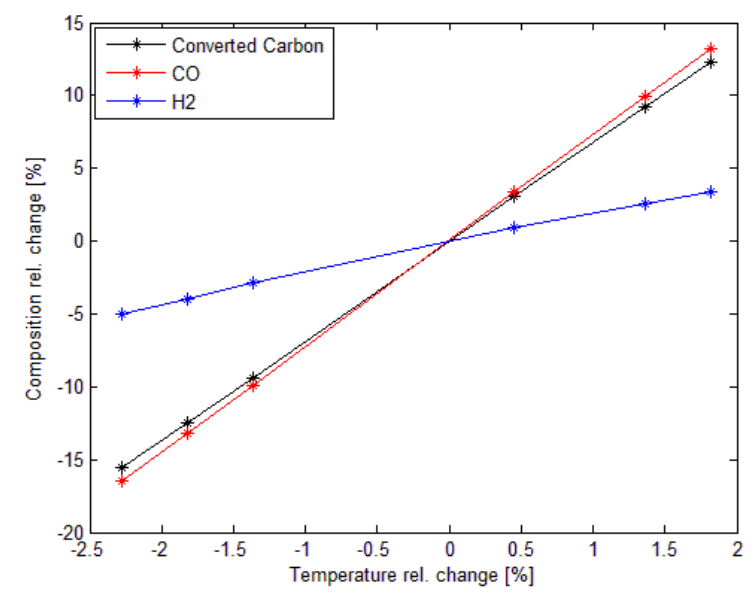

Figure 9. Model Response to Temperature Deviations.

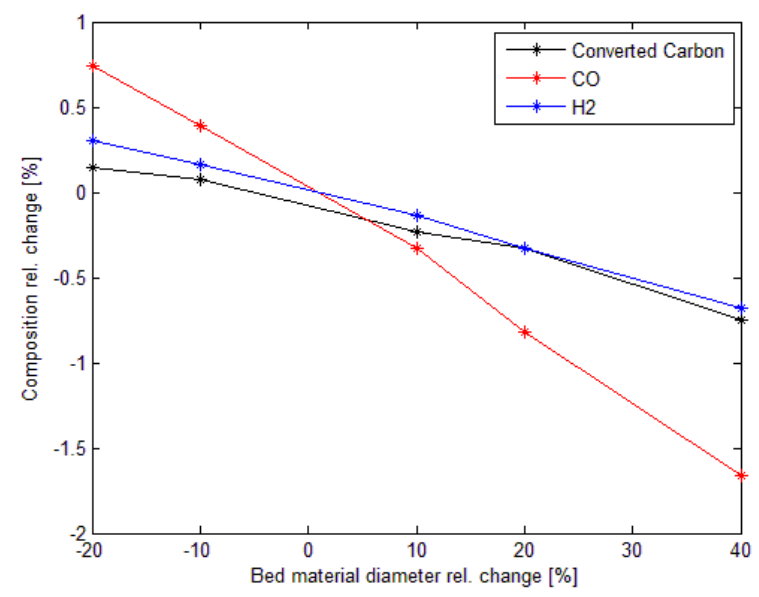

Figure 10. Model Response to Deviation of Bed Material' Particle Diameter.

\section{Conclusions}

In this paper, a model for predicting the kinetics of biomass gasification in a constant temperature bubbling fluidized bed reactor with circulating bed material is developed. In developing the model, effects of convection and diffusion of species in the reaction zone are neglected, and ideal mixing condition is assumed. The influence of bed material circulation on char residue reduction and the total reaction volume change due to char conversion and bubbling of the bed are captured. Two kinetics rate constants (Case 1 and Case2) are used to test the model and their results show that conversion of char and composition of the product gas depend on the kinetic rate constants. Case 2 model gives results closer to a 3D model based on Barracuda VR. The sensitivity analysis shows that the output of the model strongly depends on temperature and slightly depends on the bed material particles size.

The proposed model forms a basis for further work to develop a more detailed model that takes into account, 
diffusion and convection of the reacting species as well as the dynamic of temperature.

\section{References}

A. Farooq, M. Ghauri, M. H. Jaffery, and K. Shahzad (2013): Modeling of Biomass Gasification with $\mathrm{CO}_{2}$ as Gasifying Agent. Journal of Sci. Int. (Lahore), 25(3): 497-500, 2013.

A.A. Amsden, P.J. O'Rourke, and T.D. Butler (1989): A Computer Program for Chemically Reactive Flows with Sprays. Los Alamos National Laboratory, 1989.

D. Fiaschi, and M. Michelini (2001): A Two-Phase OneDimensional Biomass Gasification Kinetics Model. Journal of Biomass and Bioenergy, 21: 121-132, 2001.

D. Snider, and S. Banerjee (2010): Heterogeneous Gas Chemistry in the CPFD Eulerian-Lagrangian numerical scheme (ozone decomposition). Journal of Powder, 199(1): 100-106, 2010.

D.S. Boyalakuntla (2003): Simulation of Granular and GasSolid Flows Using Discrete Element. Department of Mechanical Engineering, Carnegie Mellon University, pp.74, 2003.

F. Fantozzi, S. Colatoni, P. Bartocci, and U. Desider (2007): Rotary Kiln Slow Pyrolysis for Syngas and Char Production from Biomass and Waste - Part II: Introducing Product Yields in the Energy Balance. Journal of Engineering for Gas Turbines and Power, 129: 908-913, 2007.

doi:10.1115/1.2720539.

F. Herning, and L. Zipperer (1936): Calculation of the Viscosity of Technical Gas Mixtures from Viscosity of the Individual Gases. Gas-Und Wasserfach, 79: 69-73, 1936.

J. Xie, W. Zhong, B. Jin, Y. Shao, and H. Liu (2012). Simulation on Gasification of Forestry Residues in Fluidized Beds by Eulerian-Lagrangian Approach. Journal of Bioresource Technology, 121: 36-46, 2012.

doi:10.1016/j.biotech.2012.06.080.

P. Lü, X. Kong, C. Wu, Z. Yuan, L. Ma, and J. Chang (2008): Modeling and Simulation of Biomass Air-Steam Gasification in a Fluidized Bed. Journal of Chem. Eng. China, 2(2): 209-213, 2008.

doi:10.1007/s11705-008-0039-7

Q. Xu, S. Pang, and T. Levi (2011): Reaction Kinetics and Producer Gas Compositions of Steam Gasification of Coal and Biomass Blend Char, Part 2: Mathematical Modelling and Model Validation. Journal of Chemical Engineering

Science, 66: 2232-2240, 2011.

doi:10.1016/j.ces.2011.02.054.

R. Radmanesh, J. Chaouki, and C. Guy (2006): Biomass Gasification in a Bubbling Fluidized Bed Reactor: Experiments and Modeling. Journal of American Institute of Chemical Engineers, 52(12): 4258-4272, 2006. doi:10.1002/aic.11020.
R.K. Thapa, C. Pfeifer, and B.M. Halvorsen (2014): Modeling of Reaction Kinetics in Bubbling Fluidized Bed Biomass Gasification Reactor. Internal Journal of Energy and Environment, 5(1): 35-44, 2014.

R.L. Braun, R.G. Mallon, and H.Y. Sohn (1981): Analysis of Multiple Gas-Solid Reactions during the Gasification of Char in Oil Shale Blocks. InProc. 14th Oil Shale Symposium, Colorado School of Mines Press, Golden, Colo, pp. 289-300, 1981.

Y.Haseli, J.A.V Oijen, and L.P.H. de Goey (2011): A Detailed One-Dimensional Model of Combustion of a Woody Biomass Particle. Journal of Bioresource Technology, 102, 9772-9782, 2011.

doi:10.1016/j.biotech.2011.07.075.

\section{Notations}

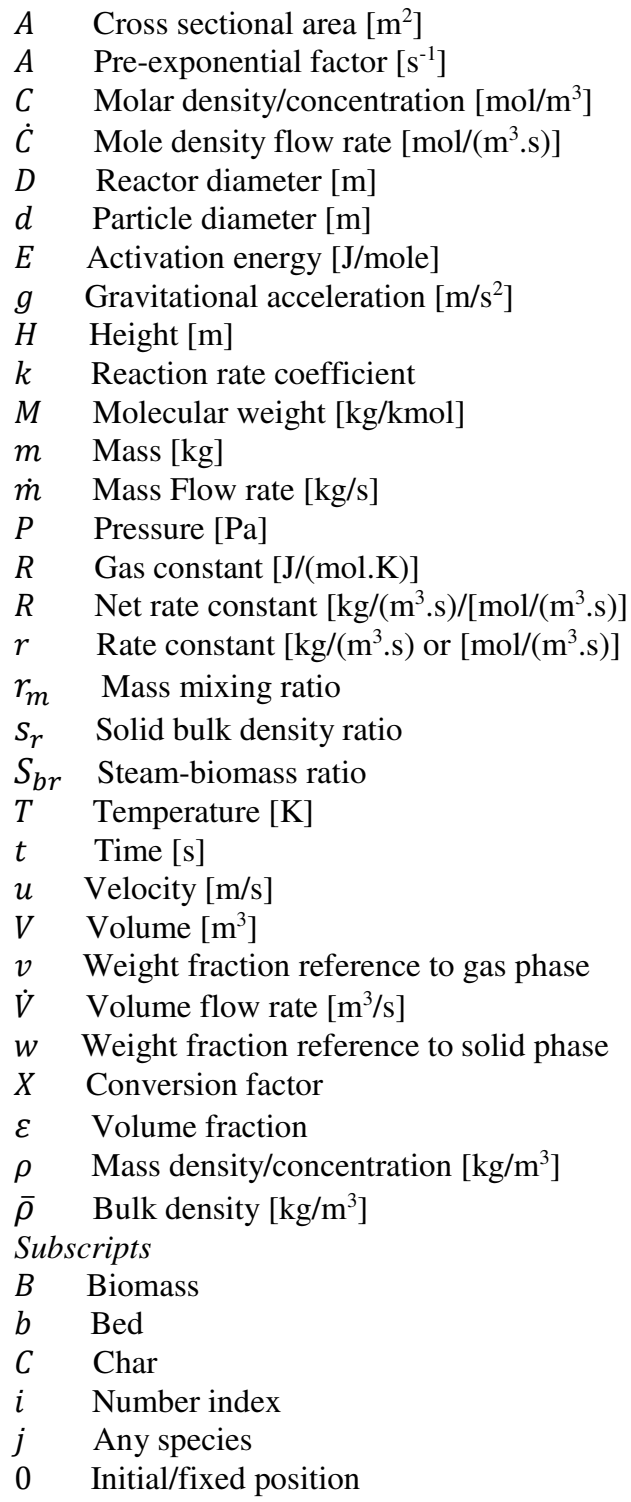

